\title{
$\mathrm{P} 224$
}

\section{The Tellus Airborne Geophysical Survey of Northern Ireland - Final Results}

D. Beamish (British Geological Survey), R.J. Cuss (British Geological Survey), M. Kurimo (Geological Survey of Finland), M. Lahti (British Geological Survey), H. Leväniemi (Geological Survey of Finland) \& E. Tartaras* (British Geological Survey)

EAGE 69th Conference \& Exhibition — London, UK, 11 - 14 June 2007

DOI 10.3997/2214-4609.201401884

\section{SUMMARY}

The Tellus airborne geophysical survey of Northern Ireland was conducted over a two year period. Measurements from a fixed-wing aircraft operating at $56 \mathrm{~m}$ include magnetic (gradiometer), radiometric and frequency-domain electromagnetic. The survey comprises over 80,000 line-km of coverage and was completed in two phases (2005 and 2006). The large geographical scale and two year duration have combined to raise interesting questions regarding data processing and seasonal adjustments. The radiometric and electromagnetic data sets are completely new for N.Ireland, whereas the magnetic data set is significantly better than the existing one. The preliminary results have excited the interest of the planning, mineral and environmental communities. 


\section{Introduction}

The Tellus airborne geophysical survey of Northern Ireland was conducted over a two year period by the Joint Airborne geoscience Capability (JAC). This facility, formed by the Finnish and British Geological Surveys (GTK and BGS), provides both partners with a costeffective means of acquiring high-resolution airborne data for their national strategic science programmes. Northern Ireland was the first part of the UK to conduct an independent costbenefit analysis and recognise the benefits of modern, high-resolution aerogeophysical surveying. The survey was funded by the Department of Enterprise, Trade and Investment. The Tellus project was conceived as a Resource and Environmental Survey for the benefit of both public and private development sectors. The derived datasets can be used to support government policy decisions in economic and sustainable development, social infrastructure, environment and human health. The 3 main geophysical measurements (magnetic, radiometric and electromagnetic) obtained by the JAC Twin-Otter contribute to different aspects of these broad objectives. This paper describes some general results and other issues associated with the data acquired over the two year period.

\section{The 2005 (Phase 1) and 2006 (Phase 2) surveys}

The Tellus high resolution airborne geophysical survey was designed using the boundary of the geopolitical landmass of Northern Ireland, which covers an area of $14,160 \mathrm{~km}^{2}$. Flight lines were extended about $2 \mathrm{~km}$ across the landmass border, both across the land/sea interface and into the Republic of Ireland. Flight line spacing was set at an interval of $200 \mathrm{~m}$. The flight line direction (345 degrees geographic) was set on the basis of geological trends. Flight line lengths of about $50 \mathrm{~km}$ were considered optimum in terms of this specific systematic mapping programme. The complex nature of the border resulted in some short flight line lengths, particularly in the west of the survey area. The survey area was divided into 7 survey blocks labelled A to E2. The survey parameters are summarized in Table 1.

\begin{tabular}{|c|c|}
\hline Survey line spacing & $200 \mathrm{~m}$ \\
\hline Survey line direction & 345 degrees \\
\hline Minimum survey altitude (rural) & $56 \mathrm{~m}$ \\
\hline Minimum survey altitude (other) & $244 \mathrm{~m}$ \\
\hline Typical survey speed & $70 \mathrm{~m} / \mathrm{s}$ \\
\hline Magnetic sampling & $0.1 \mathrm{sec}$ \\
\hline Electromagnetic sampling & $0.25 \mathrm{sec}$ \\
\hline Radiometric sampling & $1 \mathrm{sec}$ \\
\hline GPS positional sampling & $1 \mathrm{sec}$ \\
\hline Magnetic/GPS base station sampling & $1 \mathrm{sec}$ \\
\hline PHASE 1 survey duration & 01 July to 05 October 2005 \\
\hline PHASE 2 survey duration & 29 March to 31 May 2006* \\
\hline Total line-km acquired (ideal lines) & $81,703 \mathrm{~km}$ \\
\hline
\end{tabular}

\section{Table 1. Tellus survey parameters}

A complete description of the airborne system and the processing methods used by JAC is given by Hautaneimi et al. (2005). Recently introduced research items include a laser altimeter recording at $200 \mathrm{~Hz}$ and a downward-looking digital video to record continuous, overlapping image frames. These frames can be data-based and, as such, they can provide detailed information on the geophysical responses observed. The 2 frequency EM system used in Phase 1 ( 3125 and $14368 \mathrm{~Hz}$ ) was replaced by a new 4 frequency system for Phase 2 of the project (912, 3005, 11962 and $24510 \mathrm{~Hz}$ ). 


\section{Magnetic data}

The existing onshore airborne magnetic data were acquired in 1959, using $2 \mathrm{~km}$ flight lines at an altitude of 1000 feet.
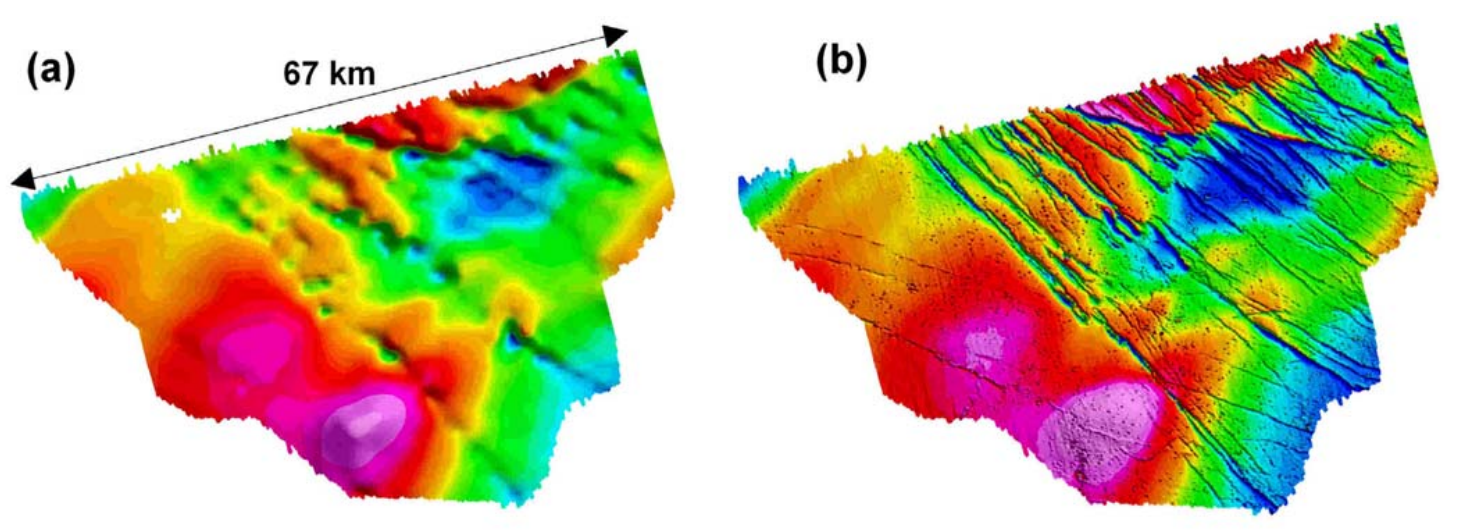

Figure 1. Existing (a) and new (b) airborne magnetic survey data from one of the five Tellus survey blocks (Block B).

The existing (1959) airborne magnetic data set for one of the survey blocks (Block B in the south-western part of N.Ireland) is shown in Figure 1a. The equivalent magnetic survey data obtained during the Phase 1 Tellus survey is compared in Figure 1b. It is evident that the decrease in flight line spacing (by a factor of 10), the much lower flight altitude (typically a factor of 5 decrease) coupled with the use of modern Caesium magnetic sensors, brings about new insights into structural associations. Large scale variations are obviously reflected in both data sets. The variations observed largely relate to concealed magnetic basement features. The prominent belt of positive anomalies in the west, are probably early Palaeozoic volcanic rocks, below the Carboniferous basin cover. The extensive dyke swarms, their trends and offsets, very evident in the new data, were unresolved by the vintage data. Also evident in the new data are large numbers of 'pimple anomalies' that represent cultural perturbations (many are individual farm buildings with metal structures/roofs). The removal of such features (magnetic deculturing) is a major issue for surveys in populated regions.

\section{Radiometric data}

Gamma ray spectroscopy principally involves the detection of the 3 natural radionuclide elements Potassium (K-40), Thorium (Th-232) and Uranium (U-238) across an energy bandwidth from 0.04 to $3 \mathrm{MeV}$. The major portion of gamma radiation is derived from the upper $30 \mathrm{~cm}$ of the subsurface. When soil horizons are present, the data may reflect either soil physical properties (e.g. grain size and moisture content) or parent (bedrock derived) properties or combinations of both. The total radiometric counts, across the whole energy window, for all of N.Ireland, are shown in Figure 2. They show a wide number of strong correlations with the geological features. Peat covered ground occurs in association with low values (cyan colour). Studies of peatland catchments may be afforded by combining both radiometric and conductivity data sets (e.g. Puranen et al., 1999).

The fact that radiometric data were collected over two seasons raised issues rarely met in airborne radiometric surveys. In order to obtain a satisfactory seasonal adjustment for all areas a linear shift was employed, similar to the method used for adjusting images in remote sensing surveys. In this case the adjusted values, $d_{a d j}$, for Phase 2 are related to the original 
values, $d$, through the relationship: $d_{a d j}=a * d+b$. The coefficients $a$ and $b$ are determined by multiple linear regression. The coefficient $a$ is a gain factor and $b$ is a DC level shift.

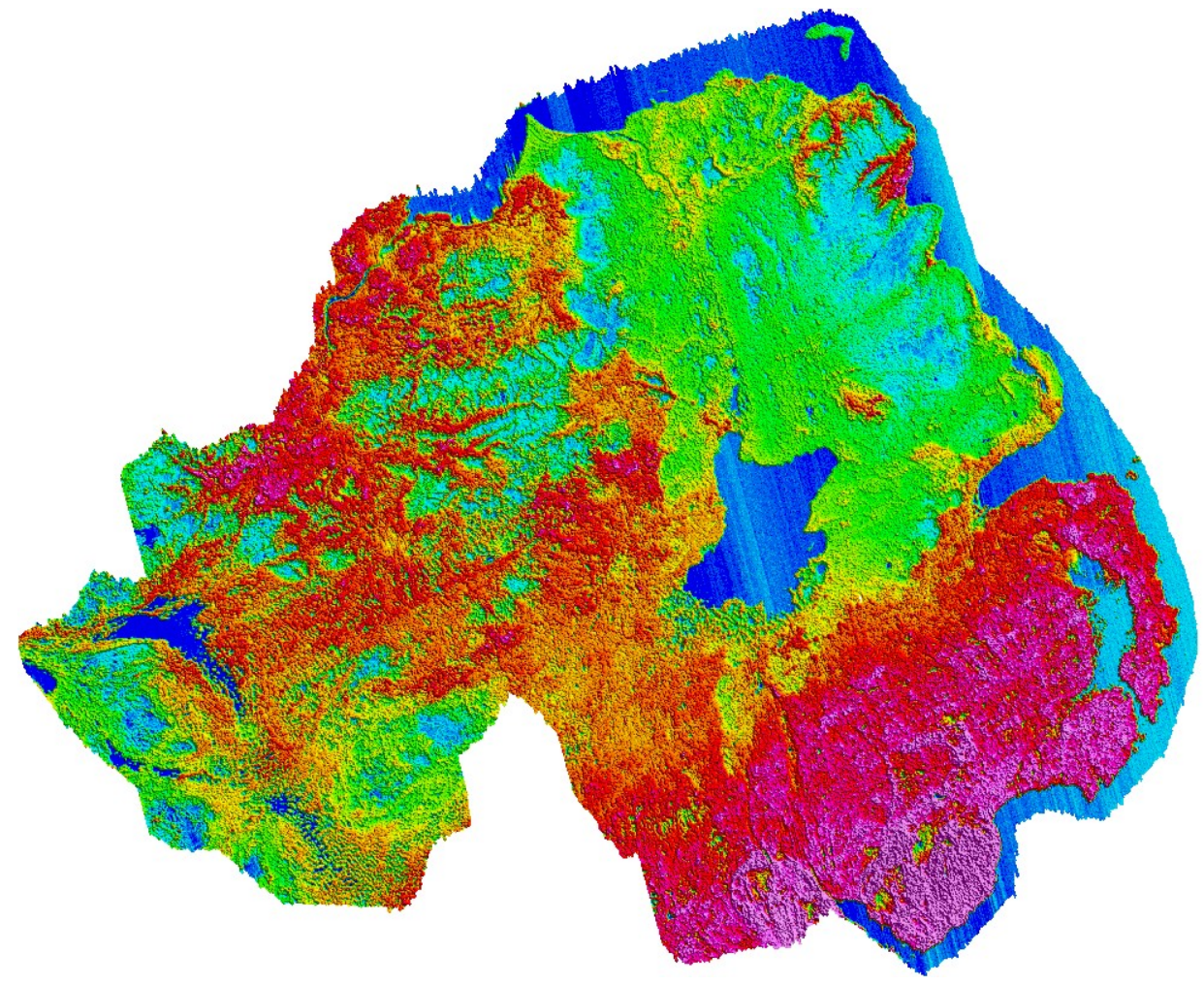

Figure 2. Total Count radiometric data map of N.Ireland.

\section{Electromagnetic (conductivity) data}

JAC procedures, as developed by GTK, include the calculation of apparent resistivity/conductivity and apparent depth, using the Fraser equivalent half-space (Suppala et al., 2005). These parameters, calculated at each frequency, provide the basic mapping capability of frequency-domain airborne EM. Previous studies (e.g. Beamish, 2004) indicate that at UK survey heights, principal sensitivities to conductivity contrasts extend to about 60 $\mathrm{m}$ in depth. In the UK geological context, even the 2 frequency system can assess both superficial (e.g. Quaternary) and bedrock relationships. As previously noted, the high resolution mapping of the bulk conductivity of geological formations constitutes new national information. Figure 3 shows the $3 \mathrm{kHz}$ apparent conductivity obtained across the entire survey area. It is evident that, as with all geophysical measurements, the data do not 'simply' map geology. The material properties involved can be complex and there are cover/bedrock relationships (thicknesses) to be taken into account when interpreting single frequency information. One of the simplest features of Figure 3a is the low conductivities (blue/green colours) that would be associated with the tightest (lowest porosity) formations. 


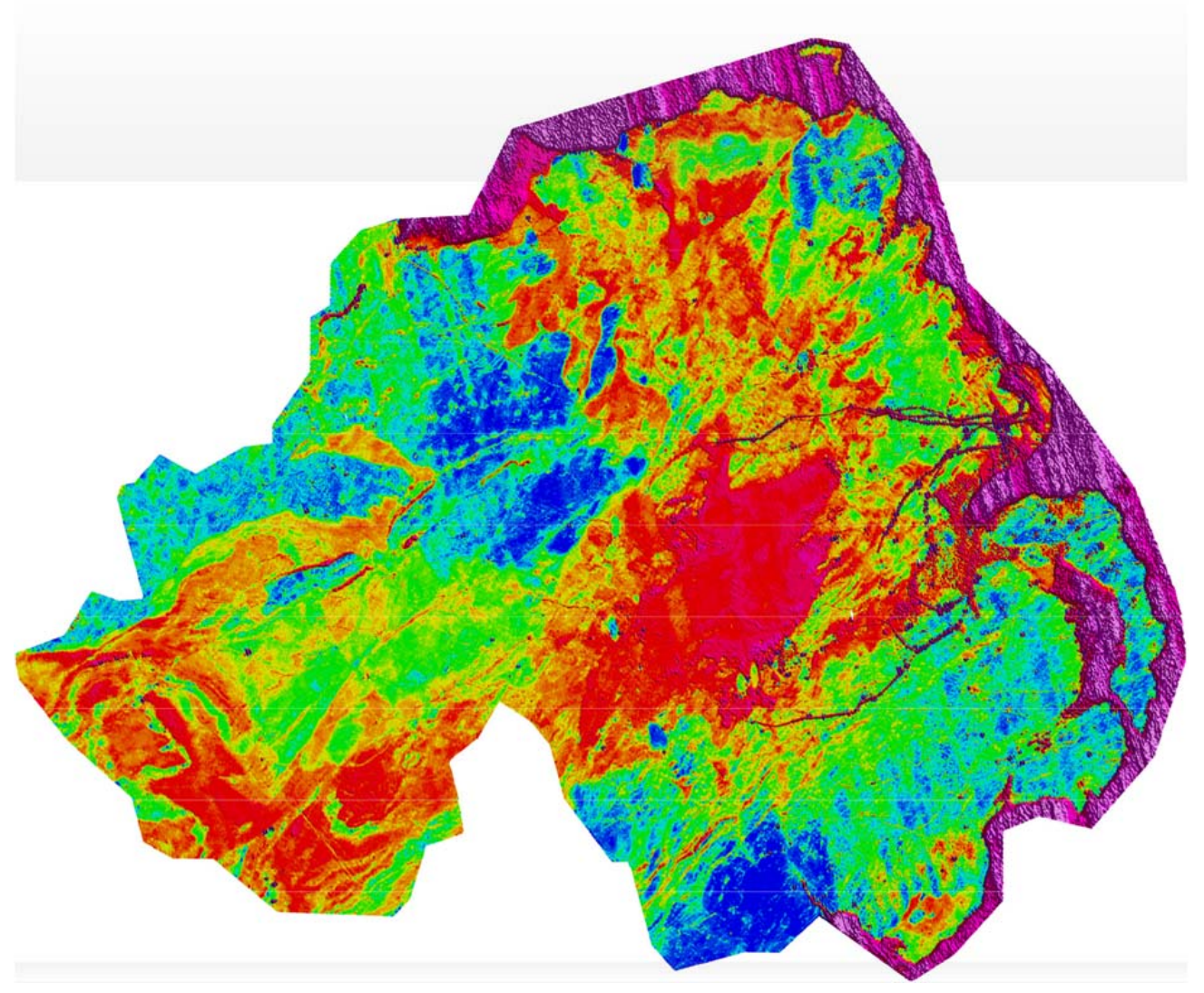

Figure 5. Apparent conductivity map of N.Ireland obtained from the $3 \mathrm{kHz}$ data.

\section{Conclusions}

The aerogeophysical survey of N. Ireland has provided completely new (radiometric and electromagnetic) or drastically improved (magnetic) data sets. These data will provide a better understanding of local geology and will aid local authorities and companies make better decisions on environmental and exploration projects. Due to its large geographical scale and two year duration, this airborne survey has also raised interesting questions regarding data processing and seasonal adjustments.

\section{References}

Beamish, D. [2004]. Airborne EM skin depths. Geophysical Prospecting, 52, 439-449.

Hautaniemi, H., Kurimo, M., Multala, J., Leväniemi, H., and Vironmäki, J. [2005]. The 'three in one' aerogeophysical concept of GTK in 2004. Geological Survey of Finland, Special paper 39, 21-74.

Puranen, R., Säävuori, H., Sahala, L., Suppala, I., Mäkilä, M., and Lerssi, J. [1999] Airborne electromagnetic mapping of surficial deposits in Finland. First Break, May 1999, 145-154.

Suppala, I., Oksama, M., and Hongisto, H. [2005] GTK airborne EM system: characteristics and interpretation guidelines. Geological Survey of Finland, Special paper 39, 103-118. 